\title{
LXR, PPAR $\gamma$, and PPAR $\delta$ Agonists Are Not Sufficient to Demonstrate Therapeutic Potential against Mouse Model of Systemic Lupus Erythematosus
}

\section{Noriko Toyota Tatebe, Katsue Sunahori Watanabe, Sonia Zeggar, Sumie Hiramatsu, Minglu Yan, Takayuki Katsuyama, Eri Katsuyama, Haruki Watanabe, Ken-ei Sada, Jun Wada*}

Department of Nephrology, Rheumatology, Endocrinology and Metabolism, Okayama University Graduate School of Medicine, Dentistry and Pharmaceutical Sciences, Okayama, Japan

Email: *junwada@okayama-u.ac.jp

How to cite this paper: Tatebe, N.T., Watanabe, K.S., Zeggar, S., Hiramatsu, S., Yan, M., Katsuyama, T., Katsuyama, E., Watanabe, H., Sada, K.-E. and Wada, J. (2017) LXR, PPAR $\gamma$, and PPAR $\delta$ Agonists Are Not Sufficient to Demonstrate Therapeutic Potential against Mouse Model of Systemic Lupus Erythematosus. Open Journal of Rheumatology and Autoimmune Diseases, 7, 128-136.

https://doi.org/10.4236/ojra.2017.72012

Received: April 28, 2017

Accepted: May 28, 2017

Published: May 31, 2017

Copyright $\odot 2017$ by authors and Scientific Research Publishing Inc. This work is licensed under the Creative Commons Attribution International License (CC BY 4.0). http://creativecommons.org/licenses/by/4.0/

\begin{abstract}
Aim: We aimed to investigate whether the agonists for liver X receptor (LXR) ameliorate lupus-like phenotypes in mice mediated by the clearance of apoptotic cells, and compare with peroxisome proliferator-activated receptor (PPAR) $\gamma$ plus $\operatorname{PPAR} \delta$ agonists, which also facilitate the clearance of apoptotic cells and exert anti-inflammatory effects in systemic lupus erythematosus (SLE). Methods: We investigated the efficacy of LXR agonist (GW3965) or dual treatment of PPAR $\gamma$ (pioglitazone) and $\operatorname{PPAR} \delta$ (GW0742) agonists in SLE animal models, female $\mathrm{MRL} / \mathrm{MpJ}-\mathrm{Fas}<\mathrm{lpr}>/ \mathrm{J}$ mice and $\mathrm{BALB} / \mathrm{cAJcl}$ mice treated with pristane. The data were analyzed with one-way analysis of variance and Tukey's honestly significant difference tests. Results: The treatment with LXR or PPAR $\gamma / \delta$ agonists did not significantly alter the swelling of lymph nodes, ds-DNA production, albuminuria, histological score of glomerular lesions, and mRNA expression of target genes including Abcal, C1qa, Icam1, Mertk and Tnf. Conclusion: LXR or PPAR $\gamma / \delta$ agonists targeting the impaired clearance for apoptosis cells may not be efficient in the remission induction therapy in SLE.
\end{abstract}

\section{Keywords}

Nuclear Receptors, Liver X Receptor (LXR), Peroxisome

Proliferator-Activated Receptor (PPAR), Systemic Lupus Erythematosus (SLE)

\section{Introduction}

Systemic lupus erythematosus (SLE) is an inflammatory autoimmune disease 
with systemic organ involvements and the current therapies are limited to suboptimal treatments. Peroxisome proliferator-activated receptor $\gamma(\operatorname{PPAR} \gamma)$ agonists are widely prescribed for the pharmacological treatment of type 2 diabetes by their insulin-sensitizing properties. PPAR $\gamma$ agonists also exert anti-inflammatory and immunomodulatory effects, and the beneficial impacts of rosiglitazone were reported for the amelioration of the autoantibody production, renal disease, and atherosclerosis in MRL-Ipr mice depending on the induction of adiponectin [1] and also in NZBWF1 mice [2]. SLE is associated with increased circulating apoptotic autoantigens and increased type I interferon (IFN) signaling which simulate the production of autoantibody including anti-dsDNA antibodies [3]. Genetic depletion of PPAR $\delta$ decreased the expression of opsonins such as $C 1 q b$ and Mertk, which was resulted in the impairment of clearance for apoptotic cells and autoimmune kidney disease resembling lupus nephritis in human [4]. Engulfment of apoptotic cells by macrophages activated liver X receptor (LXR) and induced the transcriptional activation of Mertk. The lack of LXR also manifested the defects of self-tolerance and developed autoimmune glomerulonephritis [5]. Thus, the administration of $\operatorname{PPAR} \delta$ agonist or LXR agonist may be beneficial for the treatment of SLE by enhancing the clearance of apoptotic bodies. The efforts were made to develop the $\operatorname{PPAR} \gamma / \delta$ dual agonists without the deleterious side effects associated with full $\operatorname{PPAR} \gamma$ agonists such as weight gain, edema and osteoporosis [6] and simultaneous stimulation of both $\operatorname{PPAR} \gamma$ and $\operatorname{PPAR} \delta$ may be beneficial in the treatment of SLE. In the current investigation, we explored the efficacy of LXR agonist (GW3965) or dual treatment of PPAR $\gamma$ (pioglitazone) and PPAR $\delta$ (GW0742) agonists in SLE animal model in mice, female MRL/MpJ-Fas $<$ lpr $>/ J$ miceand BALB/cAJcl mice treated with pristane.

\section{Methods}

\subsection{Animal}

Female MRL/MpJ-Fas $<$ lpr $>/$ J (MRL) mice at 8 weeks of age (Jackson) were used for animal experiments. The animals were divided into 3 groups, MRL/MpJFas $<$ lpr $>/$ J mice (MRL; $\mathrm{n}=10$ ), treated with $20 \mathrm{mg} / \mathrm{kg} /$ day of GW3965 (LXR; $\mathrm{n}$ $=8)$, and treated with $25 \mathrm{mg} / \mathrm{kg} / \mathrm{day}$ of pioglitazone and $1 \mathrm{mg} / \mathrm{kg} /$ day of GW0742 (PPAR $\gamma / \delta ; \mathrm{n}=9$ ) (Sigma-Aldrich) from 8 to 20 weeks of age. For preparation of stock solutions, $100 \mathrm{mg}$ of GW3965, $125 \mathrm{mg}$ of pioglitazone, and $5 \mathrm{mg}$ of GW0742 were dissolved in $200 \mu \mathrm{g}$ DMSO and mixed with $125 \mathrm{mg}$ of hydroxyl methylcellulose. Water was added to total volume of $25 \mathrm{ml}$ and they were kept in $-20^{\circ} \mathrm{C}$ for further use. Sera and urine samples were collected at 14 weeks of age, and they were sacrificed at 20 weeks of age and used for following experiments. Feeding needle was used for oral administration of agents for 3 times per week.

Female $\mathrm{BALB} / \mathrm{cAJcl}$ mice (CLEA Japan) were injected with pristane at 10 weeks of age and they were divided into three groups, control $(B A L B / c ; n=10)$, $20 \mathrm{mg} / \mathrm{kg} /$ day of GW3965 treated (LXR; $\mathrm{n}=11$ ), and $25 \mathrm{mg} / \mathrm{kg} /$ day of pioglita- 
zone plus $1 \mathrm{mg} / \mathrm{kg} /$ day of GW0742 treated $(\operatorname{PPAR} \gamma / \delta ; \mathrm{n}=10)($ Sigma-Aldrich) groups from 11 to 23 weeks of age. Sera and urine samples were collected at 17 weeks of age, and they were sacrificed at 23 weeks of age and used for following experiments.

The methods were carried out in accordance with the approved guidelines. All experimental protocols were approved by the Animal Care and Use Committee of the Department of Animal Resources, Advanced Science Research Center, Okayama University.

\subsection{Measurement of Urinary Albumin Excretion and dsDNA Antibodies}

Urinary albumin excretions were measured with mouse albumin ELISA kit (Shibayagi, Japan) and standardized by the concentrations of urine creatinine. dsDNA antibodies were measured with mouse anti-dsDNA ELISA kit (Shibayagi, Japan).

\subsection{Histopathology and Scoring}

Kidney specimens were fixed with $10 \%$ buffered formalin and embedded in paraffin. Serial $2-\mu \mathrm{m}$ sections were stained with periodic acid Schiff (PAS) for histological examination by light microscopy. Glomerular lesions were graded according to reported criteria: grade 0 , no recognizable lesion in glomeruli; grade 1 , mild cell proliferation and/or cell infiltration; grade 2, the same as grade 1 with mesangial proliferation, lobulation and hyaline droplet, associated with macrophage infiltration; grade 3 , the same as grade 2 with crescent and granuloma formation and/or hyalinosis [7]. Glomeruli of more than 20 renal glomeruli examined in each mouse.

\subsection{Real-Time RT-PCR}

Kidney tissues were homogenized by Tissuelyser Adapter Set 2X24 (QIAGEN) with $1 \mathrm{ml}$ QIAzolLysis Reagent (QIAGEN) and total RNAs extracted by RNeasy Lipid Tissue Mini Kit (QIAGEN). Then, $1 \mu \mathrm{g}$ total RNAs were used to synthesize cDNA by using High Capacity RNA-to-cDNA Kit (Applied Biosystems). Quantitative real-time PCR was performed in Step One Plus Real-Time PCR System (Applied Biosystems) with specific primers and Universal Master Mix II (Life Technologies) and TaqMan Gene Expression Assays to evaluate the gene expression of intercellular adhesion molecule 1 (Mm00516023_m1), tumor necrosis factor (Mm00443258_m1), complement component 1, q subcomponent, alpha polypeptide (Mm00432142_m1), ATP-binding cassette, sub-family A (ABC1), member 1 (Mm00442646_m1), c-mer proto-oncogene tyrosine kinase (Mm00434920_m1). The relative abundance of mRNAs was standardized with GAPDH mRNA as the invariant control.

\subsection{Statistical Analysis}

Data are expressed as the mean \pm standard error. The data were also analyzed 
with one-way analysis of variance and Tukey's honestly significant difference test when multiple comparisons against the control were required. $\mathrm{P}<0.05$ was regarded as statistically significant. Pearson's $\chi^{2}$ test was used to compare the distribution of glomeruli with grading scores from 0 to 3 . The data were analyzed with JMP 8.0.2 software package (SAS Institute Inc.).

\section{Results}

\subsection{Effects of LXR Agonist and PPAR $\gamma / \delta$ Agonists in MRL Mice}

MRL mice at 8 weeks of age were administered with LXR or dual treatment of $\operatorname{PPAR} \gamma$ and $\operatorname{PPAR} \delta(\operatorname{PPAR} \gamma / \delta$ ) agonists for 12 weeks. There were no statistically significant differences in body, kidney and lymph node weights in PPAR $\gamma / \delta$ and LXR groups compared with MRL group (Figures 1(a)-1(d)). In MRL group, urine albumin-to-creatinine ratio (UACR) progressively increased at 14 and 20 weeks of age. At 20 weeks of age, the treatments with LXR agonist or PPAR $\gamma / \delta$ agonists demonstrated the reduction of UACR; however, it did not reach statistical differences (Figure 1(e)). The administration of PPAR $\gamma / \delta$ agonists did not demonstrate therapeutic effects on the tiler of anti-dsDNA antibodies. The titer of anti-dsDNA antibodies in LXR group was rather elevated and deteriorated compared with MRLmice with significant difference $(p=0.002)$ (Figure $1(f)$ ). We next performed the histopathological grading of glomerular lesions as previously described [7]. The treatments with $\operatorname{PPAR} \gamma / \delta$ and LXR agonists reduced the average scores of glomerular lesions but they were not statistically significant (Figure 2(a)). Furthermore, the distribution of glomeruli with grading scores from 0 to 3 was not significantly altered by the treatments with $\operatorname{PPAR} \gamma / \delta$ and LXR agonists (Figure 2(b) and Figure 2(c)). The genes such as Abcal, Clqa, and Mertkare under the transcriptional control of $\operatorname{PPAR} \gamma, \operatorname{PPAR} \delta$, and LXR, respectively, in addition, the genes related to inflammation, Icam1 and Tnf, may be suppressed by $\operatorname{PPAR} \gamma$ agonists. The mRNA expression of these genes were reduced in PPAR $\gamma / \delta$ and LXR groups compared with MRL mice, but they were not statistically significant again (Figure $2(\mathrm{~d})$ ). Taken together, the administration of LXR or PPAR $\gamma / \delta$ agonists into MRL mice demonstrated the tendency to ameliorate the albuminuria and histological scores in MRL mice; however, it did not exhibit sufficient therapeutic potential against glomerulonephritis in MRL mice.

\subsection{Effects of LXR Agonist and PPAR $\gamma / \delta$ Agonists in Pristane-Treated BALB/cAJcl Mice}

Female MRL mice demonstrate the "severe" disease phenotype with an average lifespan of 17 weeks and we further tested the preventive effects of PPAR $\gamma / \delta$ and LXR agonists in pristane-treated BALB/cAJcl $(\mathrm{BALB} / \mathrm{c})$ mice with milder phenotype of lupus and glomerulonephritis. There were no statistically significant differences in body, kidney and lymph node weights in PPAR $\gamma / \delta$ and LXR groups compared with $\mathrm{BALB} / \mathrm{c}$ mice treated with pristane (Figure $3(\mathrm{a})$ and Figure $3(\mathrm{~b}))$. The administration of PPAR $\gamma / \delta$ and LXR agonists did not alter the 


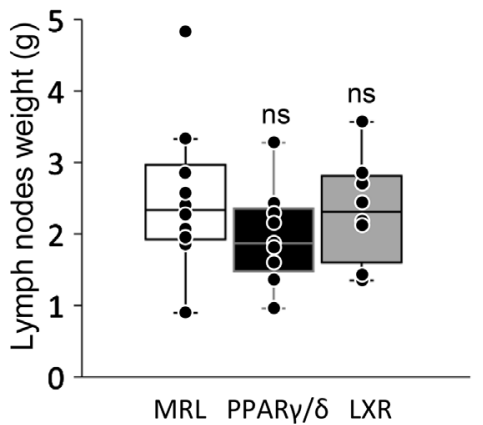

(a)

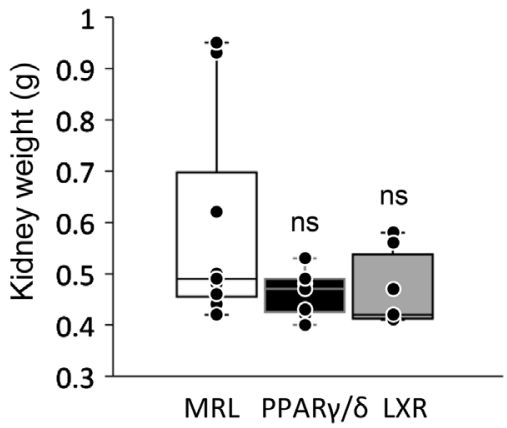

(c)

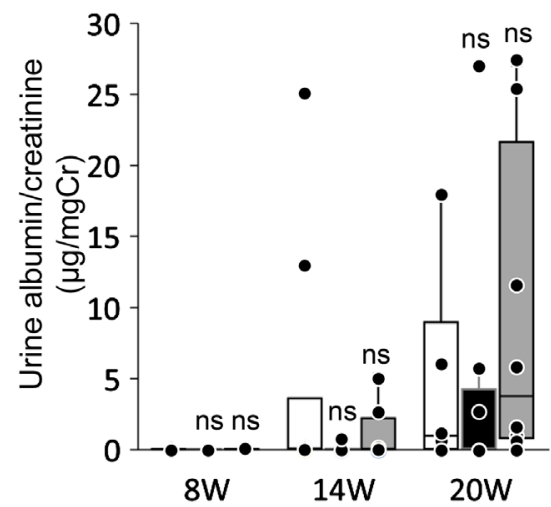

(e)

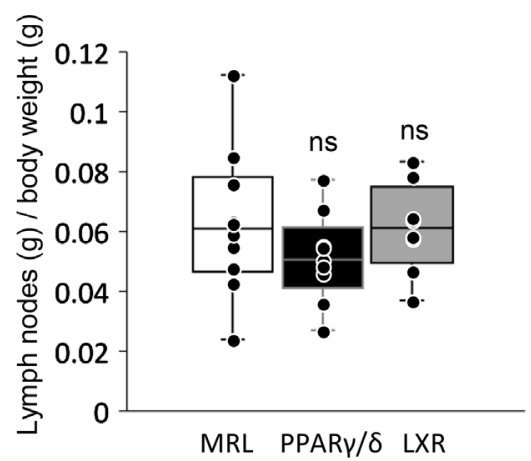

(b)

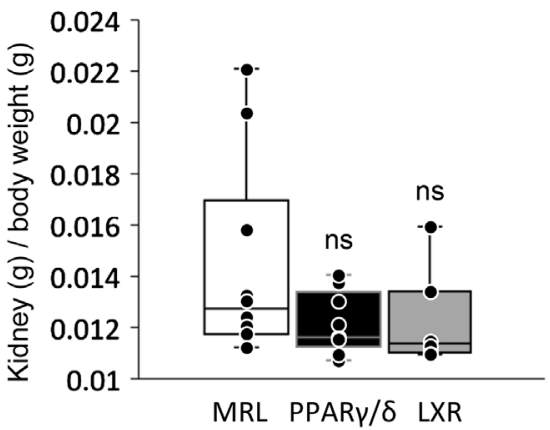

(d)

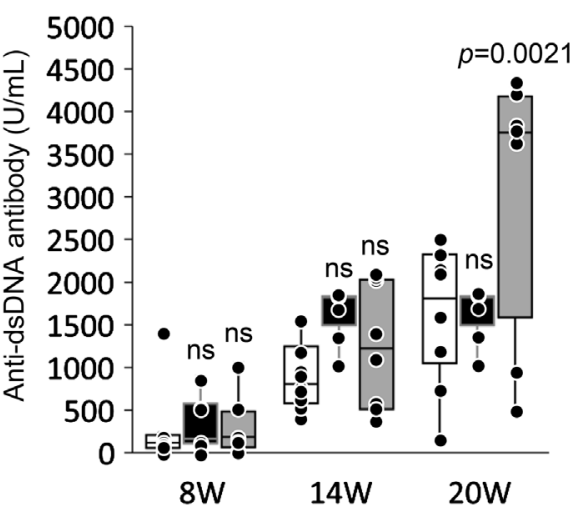

(f)

Figure 1. The administration of LXR agonist (GW3965) (LXR) or dual treatment of $\operatorname{PPAR} \gamma$ (pioglitazone) and $\operatorname{PPAR} \delta$ (GW0742) agonists (PPAR $\gamma / \delta$ ) in MRL/MpJ-Fas $<$ lpr $>/$ J (MRL) mice. (a) Lymph nodes weight, (b) Lymph nodes/body weight, (c) Kidney weight, (d) Kidney/body weight, (e) Urine albumin/creatinine, (f) Anti-dsDNA antibody. ns, not significant.

urinary excretion of albumin (Figure $3(\mathrm{c})$ ). The glomeruli in BALB/c mice treated with pristane demonstrated mild proliferation of glomerular cells but there were no differences in PPAR $\gamma / \delta$ and LXR groups compared with BALB/c mice with pristane.

\section{Discussion}

In the current investigation, LXR or dual treatment of $\operatorname{PPAR} \gamma / \delta$ agonists demonstrated only minimal beneficial effects in the treatment of established and severe autoimmune phenotypes in MRL mice. We also tested the efficacy of LXR 


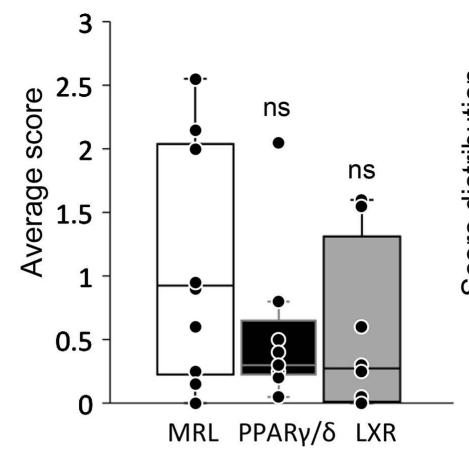

(a)
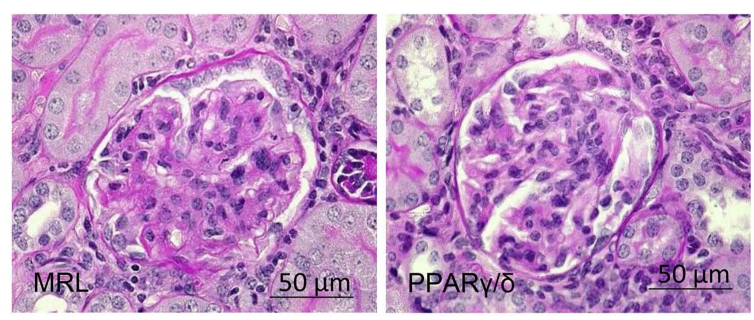

(c)

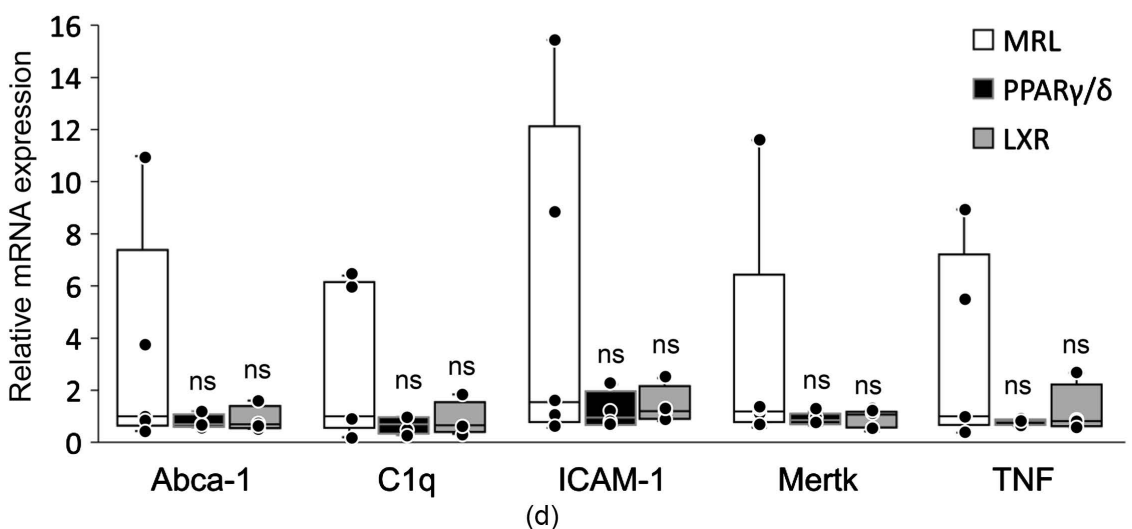

(d)

Figure 2. Histology scoring and RT-PCR in MRL/MpJ-Fas $<$ lpr $>/ J$ (MRL) mice and mice treated with LXR agonist (GW3965) (LXR) or dual treatment of PPAR $\gamma$ (pioglitazone) and PPAR $\delta$ (GW0742) agonists (PPAR $\gamma / \delta$ ). (a) Average score, (b) Score distribution, (c) PAS stain of kidney tissues, (d) Quantitative RT-PCR. ns, not significant.

or $\operatorname{PPAR} \gamma / \delta$ agonists in BALB/c mice treated with pristane with mild autoimmune phenotypes and again it demonstrated the minimal therapeutic potential. Recent work suggested that PPAR $\gamma$ agonist treatment started before disease onset demonstrated the marked amelioration of disease, while it was not effective when started after disease onset [8]. We thought that the administration of LXR or PPAR $\gamma / \delta$ agonists at 8 weeks of age might be too late to suppress the disease and we administered them immediately after the injection of pristane in BALB/C mice; however, they did not reveal the beneficial effects in prevention. The interventions to enhance the clearance of apoptotic body may not be sufficient to suppress the autoimmune phenotypes in SLE. In addition, PPAR $\gamma$ agonist is known to be beneficial to ameliorate the chronic or subclinical inflammation; however, it may not be effective to suppress the acute and severe inflammatory 


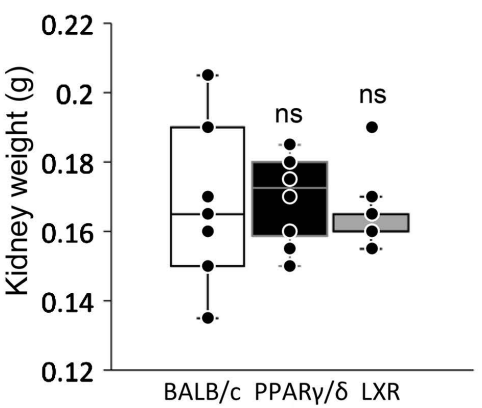

(a)
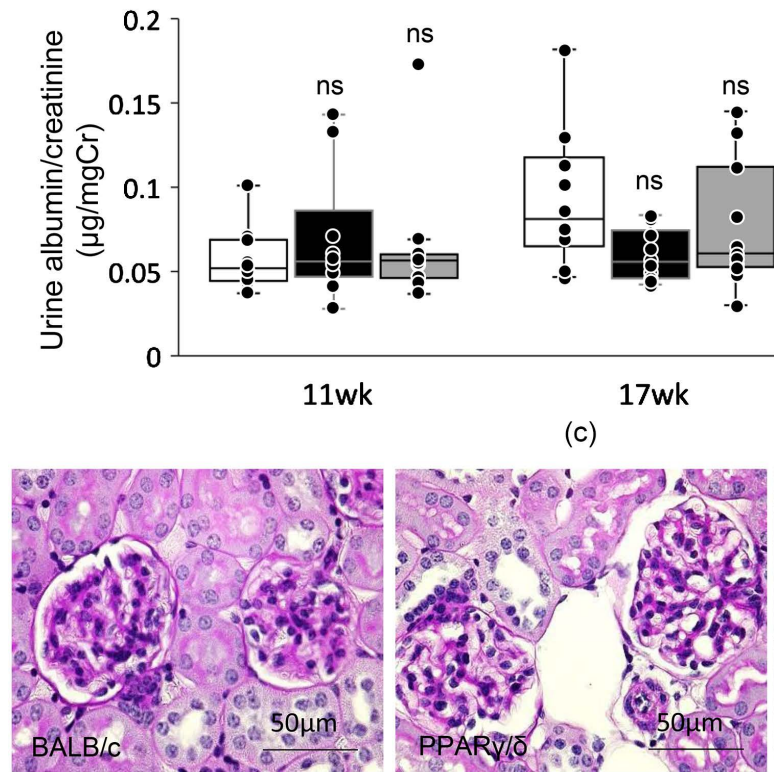

(d)

(c)

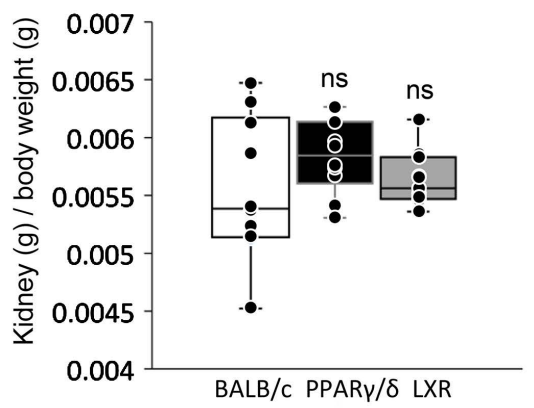

(b)
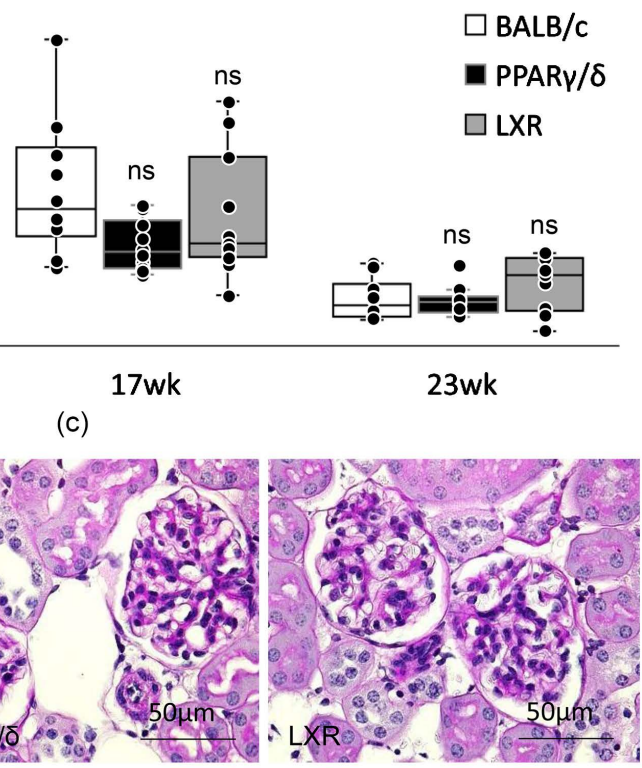

Figure 3. The administration of LXR agonist (GW3965) (LXR) or dual treatment of $\operatorname{PPAR} \gamma$ (pioglitazone) and $\operatorname{PPAR} \delta$ (GW0742) agonists (PPAR $\gamma / \delta$ ) in BALB/cAJcl mice treated with pristane. (a) Kidney weight, (b) Kidney/body weight, (c) Urine albumin/ creatinine, (d) PAS stain of kidney tissues. ns, not significant.

response in SLE. In gld. apoE (-/-) with accelerated atherosclerosis and SLE, $\operatorname{PPAR} \gamma$ agonist demonstrated the marked amelioration in atherosclerosis and minimal impacts on autoimmune phenotype such as autoantibody production [8].

The ineffectiveness of LXR or PPAR $\gamma / \delta$ agonists in lupus animal models was also explained by the unfavorable changes in global gene expression profiles or alterations in endogenous lipid ligands. The stimulation of nuclear receptors may induce both favorable and unwanted changes in mRNA expression profile, although we did not perform the profiling such as DNA microarray. In addition, PPAR $\gamma$ and LXR bind to various physiological lipid ligands such as unsaturated fatty acids and hydroxylcholesterol, respectively [9], and the alterations of such lipid ligands also influence the activation of nuclear receptors.

The limitation of current study is that we did not investigate the dose-effect relationship and the higher doses may exert the beneficial effects on SLE, although we employed the doses which were used in previous studies. Second, we 
did not investigate the simultaneous use of steroids or immune suppressants with LXR or PPAR $\gamma / \delta$ agonists, which might be beneficial in the treatment of SLE. Finally, the results in SLE animal models in mice may not be applicable to human and the clinical studies have not been performed since LXR and PPAR $\delta$ agonists have not been approved so far in the market.

\section{Conclusion}

The use of nuclear receptor agonists such as LXR or PPAR $\gamma / \delta$ agonists seems to be not effective in the treatment of MRL and pristane-treated BALB/c mice. Efficacy of LXR or PPAR $\gamma / \delta$ agonists may be tested in the patients with SLE in combination with steroids and immune suppressants.

\section{Competing Interests}

The authors declare to have no competing interests.

\section{Funding}

This work was supported by JSPS Grant-in-Aid for Scientific Research, Grant Numbers $(25126716,26293218)$.

\section{Author's Contributions}

Study concept: NTT, KSW, KS and JW. Animal experiments: NTT, SZ, SH, TK, and EK. RT-PCR: SH and MY. Statistical analysis: NTT and JW. Manuscript writing: NTT, KSW and JW. All authors approved the final manuscript.

\section{References}

[1] Aprahamian, T., Bonegio, R.G., Richez, C., Yasuda, K., Chiang, L.K., Sato, K., Walsh, K. and Rifkin, I.R. (2009) The Peroxisome Proliferator-Activated Receptor Gamma Agonist Rosiglitazone Ameliorates Murine Lupus by Induction of Adiponectin. Journal of Immunology, 182, 340-346.

https://doi.org/10.4049/jimmunol.182.1.340

[2] Venegas-Pont, M., Sartori-Valinotti, J.C., Maric, C., Racusen, L.C., Glover, P.H., McLemore Jr., G.R., Jones, A.V., Reckelhoff, J.F. and Ryan, M.J. (2009) Rosiglitazone Decreases Blood Pressure and Renal Injury in a Female Mouse Model of Systemic Lupus Erythematosus. American Journal of Physiology, Regulatory, Integrative and Comparative Physiology, 296, R1282-R1289.

https://doi.org/10.1152/ajpregu.90992.2008

[3] Li, H., Fu, Y.X., Wu, Q., Zhou, Y., Crossman, D.K., Yang, P., Li, J., Luo, B., Morel, L.M., Kabarowski, J.H., Yagita, H., Ware, C.F., Hsu, H.C. and Mountz, J.D. (2015) Interferon-Induced Mechanosensing Defects Impede Apoptotic Cell Clearance in Lupus. The Journal of Clinical Investigation, 125, 2877-2890. https://doi.org/10.1172/JCI81059

[4] Mukundan, L., Odegaard, J.I., Morel, C.R., Heredia, J.E., Mwangi, J.W., RicardoGonzalez, R.R., Goh, Y.P., Eagle, A.R., Dunn, S.E., Awakuni, J.U., Nguyen, K.D., Steinman, L., Michie, S.A. and Chawla, A. (2009) PPAR-Delta Senses and Orchestrates Clearance of Apoptotic Cells to Promote Tolerance. Nature Medicine, 15, 1266-1272. https://doi.org/10.1038/nm.2048

[5] A-Gonzalez, N., Bensinger, S.J., Hong, C., Beceiro, S., Bradley, M.N., Zelcer, N., 
Deniz, J., Ramirez, C., Diaz, M., Gallardo, G., de Galarreta, C.R., Salazar, J., Lopez, F., Edwards, P., Parks, J., Andujar, M., Tontonoz, P. and Castrillo, A. (2009) Apoptotic Cells Promote Their Own Clearance and Immune Tolerance through Activation of the Nuclear Receptor LXR. Immunity, 31, 245-258.

https://doi.org/10.1016/j.immuni.2009.06.018

[6] Gathiaka, S., Nanayakkara, G., Boncher, T., Acevedo, O., Wyble, J., Patel, S., Patel, A., Shane, M.E., Bonkowski, B., Wieczorek, J., Rong, Y., Huggins, K., Smith, F. and Amin, R.H. (2013) Design, Development and Evaluation of Novel Dual PPARdelta/PPARgamma Agonists. Bioorganic \& Medicinal Chemistry Letters, 23, 873-879.

[7] Miyazaki, T., Ono, M., Qu, W.M., Zhang, M.C., Mori, S., Nakatsuru, S., Nakamura, Y., Sawasaki, T., Endo, Y. and Nose, M. (2005) Implication of Allelic Polymorphism of Osteopontin in the Development of Lupus Nephritis in MRL/lpr Mice. European Journal of Immunology, 35, 1510-1520. https://doi.org/10.1002/eji.200425672

[8] Aprahamian, T.R., Bonegio, R.G., Weitzner, Z., Gharakhanian, R. and Rifkin, I.R. (2014) Peroxisome Proliferator-Activated Receptor Gamma Agonists in the Prevention and Treatment of Murine Systemic Lupus Erythematosus. Immunology, 142, 363-373. https://doi.org/10.1111/imm.12256

[9] Kiss, M., Czimmerer, Z. and Nagy, L. (2013) The Role of Lipid-Activated Nuclear Receptors in Shaping Macrophage and Dendritic Cell Function: From Physiology to Pathology. The Journal of Allergy and Clinical Immunology, 132, 264-286. https://doi.org/10.1016/j.jaci.2013.05.044

\section{Abbreviations}

ELISA: enzyme-linked immunosorbent assay.

GAPDH: glyceraldehyde-3-phosphate dehydrogenase.

PPAR: peroxisome proliferator-activated receptor.

SLE: systemic lupus erythematosus.

LXR: liver X receptor.

Submit or recommend next manuscript to SCIRP and we will provide best service for you:

Accepting pre-submission inquiries through Email, Facebook, LinkedIn, Twitter, etc. A wide selection of journals (inclusive of 9 subjects, more than 200 journals)

Providing 24-hour high-quality service

User-friendly online submission system

Fair and swift peer-review system

Efficient typesetting and proofreading procedure

Display of the result of downloads and visits, as well as the number of cited articles

Maximum dissemination of your research work

Submit your manuscript at: http://papersubmission.scirp.org/

Or contact ojra@scirp.org 